\title{
PERBANDINGAN PENGOMPOSAN METODE KARUNG GONI DENGAN PENGOMPOSAN DI ATAS TANAH PADA SISTEM AEROBIK
}

\author{
Dwi Wahyu Purwiningsih \\ Politeknik Kesehatan Kementerian Kesehatan Ternate \\ Email : dwiwahyupurwiningsih@gmail.com
}

\begin{abstract}
Abstrak
Latar Belakang : Sampah masih menjadi masalah di kota-kota yang ada di Indonesia tidak terkecuali di kota Ternate, timbulan sampah yang dihasilkan oleh masyarakat kota Ternate yang diangkut ke TPA yaitu $226 \mathrm{~m}^{3}$ /hari, dengan tingkat pelayanan 57\% dari total masyarakat Kota Ternate (BPS, 2015). Alternatif pengelolaan sampah yang baik untuk menghadapi permasalahan ini salah satunya dengan menggunakan teknologi tepat guna. Salah satu teknologi tepat guna yang dapat diterapkan yaitu penggunaan media pengomposan berupa karung goni.

Manfaat Penelitian : menguji teori tentang pengomposan dengan menggunakan berbagai media untuk pengomposan aerobik.

Lokasi Penelitian : di Jurusan Kesehatan Lingkungan Poltekkes Ternate.

Metode Penelitian : Jenis penelitian experimental dengan menggunakan rancangan Posstest Only Control Design. Pengolahan dan penyajian data dalam penelitian ini adalah jumlah kompos yang dihasilkan dari proses pengomposan ditimbang dan dibedakan sesuai dengan jenis media dan MOL kemudian disajikan dalam bentuk tabel dan dinarasikan.

Hasil Penelitian : Menunjukkan media yang paling banyak menghasilkan kompos adalah karung goni dengan penambahan MOL Tape Ubi dan yang paling sedikit adalah dengan pengomposan diatas tanah dengan penambahan MOL Nanas, waktu yang digunakan pada proses pengomposan selama 20 hari.

Kesimpulan : Rata-rata jumlah kompos yang paling banyak dihasilkan berturut-turut adalah dengan media karung goni dengan menggunakan MOL Tape Ubi, MOL Terasi MOL Nanas dan kontrol.
\end{abstract}

Kata Kunci : Sampah, Pengomposan, Media Karung Goni.

\section{Pendahuluan}

Sampah masih menjadi masalah di Indonesia karena pelayanan yang dilakukan saat ini masih relatif terbatas. Kota Ternate merupakan salah satu kota kecil yang berada di Provinsi Maluku Utara. Kota Ternate terdiri dari 6 kecamatan yaitu Kecamatan Ternate Utara, Ternate Selatan, Ternate Tengah, Pulau Ternate, Pulau Moti dan pulau Batang Dua, dengan total luas wilayah 5.709,58 $\mathrm{km}^{2}$ dengan jumlah penduduk 207.789 jiwa dan mengalami peningkatan dari tahun ke tahun. Timbulan sampah yang dihasilkan oleh masyarakat kota Ternate yang diangkut ke TPA yaitu $226 \mathrm{~m}^{3} /$ hari, dengan tingkat pelayanan $57 \%$ dari total masyarakat Kota Ternate. Untuk mengatasi peningkatan volume sampah, selain pihak Satuan Kerja Perangkat Daerah (SKPD) dalam hal ini Dinas Kebersihan Kota Ternate perlu ada upaya alternatif lain yang dilakukan oleh masyarakat. Alternatif pengelolaan sampah yang lebih baik untuk menghadapi permasalahan ini, salah satunya dengan menggunakan teknologi tepat guna, salah satu teknologinya yaitu menggunakan Lubang Resapan Biopori (LRB). Lubang resapan biopori "diaktifkan" dengan memberikan sampah organik kedalamnya. Sampah ini akan dijadikan sebagai sumber energi bagi organisme tanah untuk melakukan kegiatannya melalui proses dekomposisi. Sampah yang telah didekomposisi ini dikenal sebagai kompos. Kompos dapat dipanen pada setiap periode tertentu dan dapat dimanfaatkan sebagai pupuk organik pada berbagai jenis tanaman, seperti tanaman hias, sayuran, dan jenis tanaman lainnya. Selain mengolah sampah organik menjadi kompos, Lubang Resapan Biopori juga dapat meningkatkan kemampuan tanah dalam meresapkan air hujan. Saluran dan lubang dalam sistem peresapan biopori digunakan 
sebagai simpanan dalam menampung dan meresapkan air tanah. Lubang diisi dengan sampah organik untuk memicu terbentuknya biopori. Biopori adalah pori-pori berbentuk lubang (terowongan kecil) yang dibuat oleh aktivitas fauna tanah atau akar tanaman. Dalam mempercepat proses pengomposan, ada beberapa bahan dekomposer yang dipakai, misalnya dengan menggunakan MOL dan salah satunya yaitu EM4 (Effevtive microorganism 4), dalam penelitian yg dilakukan oleh Yuniwati (2010) di dapatkan hasil pembuatan kompos dengan bantuan EM4 adalah 3 hari dengan kualitas kompos yang dihasilkan memenuhi standar kualitas kompos seperti diatur dalam Peraturan Mentan No 2/Pert/HK.060/2/2006. Dengan menggunakan kondisi proses optimal (konsentrasi EM4 0,5 \% suhu proses 40 derajat Celcius, ukuran bahan $0,0356 \mathrm{~cm}$ dan konsentrasi gula $0,8 \%$. Pada proses pengomposan bahan baku yang digunakan tidak dapat mempengaruhi rasio $\mathrm{C} / \mathrm{N}$, penelitian yang dilakukan oleh Widarti (2015) di dapatkan hasil jenis sampah yang dipakai yaitu kubis dan kulit pisang serta dicampurkan dengan kotoran sapi menunjukkan tidak ada pengaruh karena 3 variasi rasio $\mathrm{C} / \mathrm{N}$ bahan baku yang digunakan masih mendekati range 20-30. Praktek pengomposan yang dilakukan oleh mahasiswa Jurusan Kesehatan Lingkungan pada bulan Maret didapatkan hasil waktu pengomposan berkisar 21-28 hari dengan berbagai macam jenis sampah organik dan dengan campuran MOL buah nanas. Pengomposan yang dilakukan langsung di dalam lubang tanah didapatkan hasil pengomposan berkisar 35-40 hari dengan berbagai macam jenis sampah tanpa ada tambahan MOL. Berdasarkan uraian di atas, peneliti tertarik untuk melakukan penelitian dengan judul Kemampuan MOL (Mikroorganisme Lokal) Pada Proses Pengomposan di Dalam Lubang Resapan Biopori.

\section{Metode}

Jenis penelitian ini adalah Experimental, penelitian ini bertujuan untuk mengetahui Efektivitas Penambahan Mol untuk proses pengomposan dalam lubang resapan biopori. Dalam penelitian ini digunakan rancangan penelitian Posttest Only Control Design. Rancangan penelitian ini untuk melihat efektivitas proses pengomposan secara aerobik. Lokasi penelitian ini dilaksanakan di Kampus B Politeknik Kesehatan Kementerian Kesehatan Ternate Jurusan Kesehatan Lingkungan. Data jumlah kompos yang dihasilkan dengan pengukuran berat kompos yang ditimbang, kemudian dikelompokkan berdasarkan jenis media dan MOL yang digunakan. Selanjutnya disajikan dalam bentuk tabel dan dinarasikan

\section{Hasil}

Tabel 1

Perbandingan jumlah sampah yang digunakan dengan jumlah MOL pada proses pengomposan sebelum pengomposan

\begin{tabular}{|c|c|c|c|c|c|}
\hline \multirow{2}{*}{ Media } & \multicolumn{3}{|c|}{ Jumlah Sampah/Jumlah } & & \multirow{3}{*}{ MOL } \\
\cline { 2 - 4 } & $\begin{array}{c}\text { MOL } \\
\text { Nanas }\end{array}$ & $\begin{array}{c}\text { MOL } \\
\text { Terasi }\end{array}$ & $\begin{array}{c}\text { MOL } \\
\text { Tape } \\
\text { Ubi }\end{array}$ & Kontrol & Ket \\
\hline $\begin{array}{c}\text { Di atas } \\
\text { Tanah }\end{array}$ & $\begin{array}{c}35 \mathrm{~kg} / 5 \\
\text { liter }\end{array}$ & $\begin{array}{c}35 \\
\mathrm{~kg} / 5\end{array}$ & $\begin{array}{c}35 \\
\mathrm{~kg} / 5\end{array}$ & $15 \mathrm{~kg}$ & \\
& & liter & liter & & \\
\hline Karung & 35 & $\begin{array}{c}35 \\
\mathrm{~kg} / 5\end{array}$ & $\begin{array}{c}35 \\
\mathrm{~kg} / 5\end{array}$ & $15 \mathrm{~kg}$ & \\
Goni & $\mathrm{kg} / 5$ & liter & & \\
& liter & liter & liter & \\
\hline
\end{tabular}

Sumber : Data Primer

Data pada tabel 1 dapat dilihat bahwa pada proses pengomposan yang dilakukan di atas tanah dan di dalam karung goni menggunakan jumlah sampah dan sebuk gergaji yang sama banyaknya yaitu masingmasing media pengomposan dan MOL yang berbeda sebanyak $35 \mathrm{~kg}$, sedangkan untuk kontrol masing-masing media menggunakan jumlah sampah sebanyak $15 \mathrm{~kg}$. MOL yang digunakan pada proses pengomposan adalah 5 liter untuk setiap media pengomposan. 
Tabel 2

Perbandingan Pengomposan di atas Tanah dan Kontrol Terhadap Jumlah Kompos yang Dihasilkan

\begin{tabular}{|c|c|c|c|}
\hline Jenis MOL & $\begin{array}{c}\text { Di atas } \\
\text { Tanah }\end{array}$ & Kontrol & Ket \\
\cline { 1 - 2 } MOL & $44,5 \%$ & \multirow{2}{*}{$30 \%$} & \\
Nanas & & & \\
\cline { 1 - 2 } MOL & $45 \%$ & & \\
Terasi & & & \\
\cline { 1 - 2 } $\begin{array}{c}\text { MOL Tape } \\
\text { Ubi }\end{array}$ & $56 \%$ & & \\
\hline
\end{tabular}

Sumber : Data Primer

Data pada tabel 2 dapat dilihat bahwa pada proses pengomposan yang dilakukan di atas tanah untuk tiga MOL berbeda adalah yang terbanyak pada MOL Tape Ubi yaitu $56 \%$ dan kompos yang dihasilkan pada kontrol adalah $30 \%$.

Tabel 3

Perbandingan Pengomposan di dalam Karung Goni dan Kontrol Terhadap Jumlah Kompos yang Dihasilkan

\begin{tabular}{|c|c|c|c|}
\hline $\begin{array}{l}\text { Jenis } \\
\text { MOL }\end{array}$ & $\begin{array}{c}\text { Di dalam } \\
\text { Karung Goni }\end{array}$ & Kontrol & Ket \\
\hline $\begin{array}{l}\text { MOL } \\
\text { Nanas }\end{array}$ & $57 \%$ & \multirow[t]{3}{*}{$47,5 \%$} & \\
\hline $\begin{array}{l}\text { MOL } \\
\text { Terasi }\end{array}$ & $65 \%$ & & \\
\hline $\begin{array}{c}\text { MOL } \\
\text { Tape } \\
\text { Ubi }\end{array}$ & $82,5 \%$ & & \\
\hline
\end{tabular}

Sumber : Data Primer

Data pada tabel 3 dapat dilihat bahwa pada proses pengomposan yang dilakukan di dalam karung goni untuk tiga MOL berbeda adalah yang terbanyak pada MOL Tape Ubi yaitu 82,5\% dan kompos yang dihasilkan pada kontrol adalah 47,5\%.

Tabel 4

Perbandingan Pengomposan di atas Tanah, di dalam Karung Goni dan Kontrol Terhadap Jumlah Kompos yang Dihasilkan

\begin{tabular}{|c|c|c|c|c|}
\hline $\begin{array}{c}\text { Jenis } \\
\text { MOL }\end{array}$ & $\begin{array}{c}\text { Di atas } \\
\text { Tanah }\end{array}$ & $\begin{array}{c}\text { Di dalam } \\
\text { Karung } \\
\text { Goni }\end{array}$ & $\begin{array}{c}\text { Rata- } \\
\text { rata }\end{array}$ & Ket \\
\hline $\begin{array}{c}\text { MOL } \\
\text { Nanas }\end{array}$ & $44,5 \%$ & $57 \%$ & $\begin{array}{c}50,75 \\
\%\end{array}$ & \\
\hline $\begin{array}{c}\text { MOL } \\
\text { Terasi }\end{array}$ & $45 \%$ & $65 \%$ & $55 \%$ & \\
\hline
\end{tabular}

\begin{tabular}{|c|c|c|c|c|}
\hline $\begin{array}{c}\text { MOL } \\
\text { Tape } \\
\text { Ubi }\end{array}$ & $56 \%$ & $82,5 \%$ & 69,25 & \\
\hline Kontrol & $30 \%$ & $47,5 \%$ & $\begin{array}{c}38,75 \\
\%\end{array}$ & \\
\hline $\begin{array}{c}\text { Total } \\
\text { Rata- } \\
\text { rata }\end{array}$ & $\mathbf{4 3 , 9 \%}$ & $\mathbf{6 3} \%$ & - & - \\
\hline
\end{tabular}

Sumber : Data Primer

Data pada tabel 4 dapat dilihat bahwa pada proses pengomposan yang dilakukan di atas tanah dan di dalam karung goni untuk tiga MOL berbeda adalah yang terbanyak menghasilkan kompos pada waktu 20 hari adalah pada media karung goni yaitu rata-rata untuk tiga jenis MOL dalah $63 \%$ dengan persentasi terbanyak pada MOL Tape ubi yaitu $82,5 \%$. Media pengomposan yang dilakukan di atas tanah dengan tiga jenis MOL berbeda rata-rata menghasilkan kompos sebanyak 43,9\% dengan persentasi terbanyak pada MOL Tape Ubi yaitu $56 \%$.

\section{Pembahasan}

Pengukuran jumlah kompos yang dihasilkan pada media karung goni dan pengomposan di atas tanah pada sistem aerobik yang berlokasi di jurusan Kesehatan lingkungan Poltekkes Ternate menggunakan sebanyak 4 karung karung goni, dengan tiga karung goni menggunakan tiga jenis MOL yang berbeda dan satu karung goni sebagai kontrol.Pembandingnya adalah pengomposan di atas tanah yang menggunakan tiga jenis MOL yang berbeda dan lokasi pengomposan yang terpisah antara penggunaan MOL yang satu dan yang lainnya, dan satu lokasi pengomposan sebagai kontrol. Pengomposan yang dilakukan untuk semua media adalah selama 20 hari, dengan menggunakan MOL Tape Ubi, MOL Terasi dan MOL Nanas.

Dari hasil yang diperoleh dapat dilihat bahwa rata-rata jumlah kompos yang dihasilkan untuk masing-masing media disimpulkan bahwa media yang paling cepat proses pengomposannya yaitu di dalam karung goni dengan menggunakan MOL Tape Ubi, MOL Terasi, MOL Nanas dan kontrol artinya tanpa MOL, sedangkan untuk jumlah 
kompos yang paling rendah dihasilkan yaitu apad pengomposan di atas tanah dengan menggunakan MOL Nanas dab kontrol.

Hasil penelitian ini sejalan dengan praktek pengomposan di dalam ruangan yang telah dilakukan oleh mahasiswa semester IV Jurusan Kesehatan Lingkungan Poltekkes Ternate (2015), dimana semua jenis sampah organik yang diolah menjadi kompos dengan menggunakan campuran MOL Tape Ubi dan MOL Nanas pada hari ke-17 menghasilkan jumlah kompos yang sudah diayak sebesar 65 $\%$ dari total jumlah sampah yang dibuat kompos.

Hasil penelitian ini sejalan dengan penelitian yang dilakukan oleh Purwiningsih, dkk (2016) yang melihat perbandingan pengomposan di dalam lubang Biopori dengan menggunakan lima jenis MOL berbeda dan lima jenis sampah yang berbeda. Hasil penelitian menunjukkan bahwa proses pengomposan yang dilakukan di dalam lubang resapan Biopori dengan menggunakan MOL Tape Ubi adalah yang paling banyak menghasilkan kompos dalam jangka waktu 20 hari.

Hasil penelitian ini sejalan dengan praktek pengomposan aerobik yang dilakukan oleh mahsiswa semester IV Jurusan Kesehatan Lingkungan Poltekkes Ternate (2016), sampah yang dibuat kompos di campur dengan MOL Nanas dan MOL Nasi basi dan ditutup bagian atasnya menggunakan karung goni selama 15 hari. Hasil pengomposan yang dilakukan menghasilkan kompos yang sudah diayak sebesar $60 \%$ dari total jumlah sampah yang dibuat kompos.

Penelitian ini bersifat penelitian baru karena dilakukan untuk mengetahui apakah penggunaan karung goni sebagai media untuk pengomposan dapat digunakan atau tidak, karena sebelumnya peneliti tidak melihat adanya penelitian serupa yang di publikasikan menggunakan karung goni sebagai media pengomposan pada sistem aerobik. Hasil penelitian menunjukkan karung goni dapat digunakan untuk mempercepat proses pengomposan aerobik dengan menambahkan
MOL sebagai bumbu kompos jika dibandingkan dengan pengomposan aerobik di atas tanah yang biasa dilakukan.

Penelitian penggunaan karung goni sebagai media pengomposan dianggap berhasil karena kompos yang dihasilkan lebih banyak dari kompos yang dihasilkan oleh pengomposan di atas tanah. Pengomposan di dalam karung goni mempunyai beberapa keuntungan jika diterapkan di pemukiman padat karena tidak membutuhkan lokasi yang luas, selain itu untuk pengomposan di dalam karung goni dapat di kontrol suhu dan kelembaban yang diinginkan. Semakin tinggi suhu semakin cepat proses pengomposan karena suhu yang tinggi menunjukkan proses perombakan yang terjadi.

\section{Kesimpulan}

Berdasarkan hasil pembahasan dapat disimpulkan bahwa :

1. Jumlah kompos yang dihasilkan pada media pengomposan karung goni adalah yang terbanyak yaitu rata-rata sebesar 63 $\%$ dengan persentase terbanyak adalah pengomposan dalam karung goni yang ditambahkan dengan MOL Tape Ubi.

2. Jumlah kompos yang dihasilkan pada media pengomposan di atas tanah adalah yang terbanyak yaitu rata-rata sebesar 43 $\%$ dengan persentase terbanyak adalah pengomposan di atas tanah yang ditambahkan dengan MOL Tape Ubi.

3. Pengomposan yang paling banyak menghasilkan kompos adalah yang dilakukan di dalam karung goni dengan menambahkan MOL Tape ubi.

\section{Saran}

Berdasarkan kesimpulan diatas dapat disarankan untuk penelitian selanjutnya dapat menggunakan berbagai aktivator lain serta media lain yang dapat digunakan di dalam proses pengomposan terutama pada sistem aerobik. 


\section{Daftar Pustaka}

Badan Pusat Statistik, 2015. Kota Ternate Dalam Angka Tahun 2015.

Bambang, dkk, 2010. Pengaruh Waktu Pengomposan Terhadap Rasio Unsur C/N dan Jumlah Kadar Air Dalam Kompos. Prosiding Pertemuan Ilmiah XXIV HFI Jateng dan DIY, Semarang.

Laporan Praktikum Mata Kuliah Penyehatan Tanah dan Pengelolaan Sampah Semester IV Jurusan Kesehatan Lingkungan Poltekkes Kemenkes Ternate, 2015.

Laporan Praktikum Mata Kuliah Penyehatan Tanah dan Pengelolaan Sampah Semester IV Jurusan Kesehatan Lingkungan Poltekkes Kemenkes Ternate, 2016.

Purwiningsih, dkk., 2017. Kemampuan Mikroorganisme Lokal (MOL) pada proses pengomposan dalam Lubang Resapan Biopori Tahun 2017. 